\title{
Mediation effect of depressive symptoms in the relationship between perceived control and wellbeing in patients with heart failure and their partners
}

Maria Liljeroos, Anna Strömberg, Kristofer Årestedt and Misook L. Chung

The self-archived postprint version of this journal article is available at Linköping University Institutional Repository (DiVA):

http:// urn.kb.se/ resolve?urn=urn:nbn:se:liu:diva-150216

N.B.: When citing this work, cite the original publication.

Liljeroos, M., Strömberg, A., Årestedt, K., Chung, M. L., (2018), Mediation effect of depressive symptoms in the relationship between perceived control and wellbeing in patients with heart failure and their partners, European J ournal of Cardiovascular Nursing, 17(6), 527-534.

https:// doi.org/ 10.1177/ 1474515118755721

Original publication available at:

https:// doi.org/ 10.1177/ 1474515118755721

Copyright: SAGE Publications (UK and US)

http:// www.uk.sagepub.com/home.nav 


\section{Mediation effect of depressive symptoms in the relationship between}

perceived control and well-being in patients with heart failure and their partners

Maria Liljeroos, RN, $\mathrm{PhD}^{1,2}$ maria.liljeroos@dll.se

Anna Strömberg, RN, PhD, FAAN, Professor ${ }^{1,3}$ anna.stromberg@liu.se

Kristofer Årestedt, RN, PhD, Professor ${ }^{1,4,5}$ kristofer.arestedt@lnu.se

Misook L, Chung, RN, PhD, FAAN Professor ${ }^{6}$ misook.chung@uky.edu

${ }^{1}$ Division of Nursing Sciences, Department of Medical and Health Sciences, Linköping University, Sweden

${ }^{2}$ Centre for Clinical Research Sörmland, Uppsala University, Eskilstuna, Sweden

${ }^{3}$ Department of Cardiology, Linköping University, Sweden

${ }^{4}$ Faculty of Health and Life Sciences, Linnaeus University, Kalmar, Sweden

${ }^{5}$ Kalmar County Council, Kalmar, Sweden

${ }^{6}$ College of Nursing, University of Kentucky, Lexington, United States

Corresponding author: Maria Liljeroos, maria.liljeroos@dll.se, phone number +46703728329, Mälarsjukhuset hospital, 63188 Eskilstuna, Sweden

Funding: This study was funded with grants from Linköping University and the Swedish Science council.

Conflicts of interest: none 


\section{Abstract}

Background: As treatment has improved, patients with heart failure (HF) live longer, and the care mostly takes place at home with partners providing the main assistance. Perceived control over HF is important in managing self-care activities to maintain health in patients and their family. Depressive symptoms are associated with impaired health status in patients with HF and their family. However, there is limited knowledge about how depressive symptoms affect the relationship between health status and perceived control over the HF in patients with HF and their cohabiting partners.

Aim: To examine whether the relationship between perceived control and health status (i.e., mental and physical) was mediated by depressive symptoms in patients with HF and their partners.

Methods: In this secondary data analysis, we included 132 HF patients and 132 partners who completed measures of depressive symptoms (the Beck Depression Inventory-II), perceived control (the Control Attitude Scale), and physical and mental health status (the Short-Form 36) instruments. The mediation effect of depression was examined using a series of multiple regression in patients and their family caregivers separately.

Results: We found a mediator effect of depressive symptoms in the relationship between perceived control and mental health status in both patients and partners. The relationship between perceived control and physical health status was mediated by depressive symptoms in the patients, not in the partners.

Conclusion: Efforts to improve self-care management and maintenance by targeting perceived control may be more effective if depressive symptoms are also effectively managed.

\section{Keywords:}

Heart failure, well-being, depressive symptoms, mediator, perceived control, family 


\section{Introduction}

Heart failure (HF) is a serious and common condition. In developed countries $1-2 \%$ of the population is diagnosed with HF and the prevalence is higher than $10 \%$ among persons above 70 years of age. ${ }^{1}$ As treatment has improved, patients with HF now live longer, and the care mostly takes place at home. ${ }^{2}$ Between $45-70 \%$ of patients with HF live with a family member who is involved in the care as an informal caregiver. When the patient and the partner are living in a dyadic relation, the partner is usually the primary caregiver. ${ }^{3}$ Supportive relationships where self-care activities could be shared with a partner are known to improve outcomes, such as self-care, adherence, and health status in patients with HF. ${ }^{4}$

Partners form a significant resource in supporting patients’ self-care, and patients and partners handle several health problems without consulting healthcare professionals. ${ }^{4}$ While partners often experience it as positive to be involved in care, ${ }^{5}$ there is also research showing that the involvement can be burdensome and that caregivers are at greater risk for impaired well-being due to the caregiving situation. ${ }^{6}$ Partners are known to experience similar mental distress as the patients, ${ }^{7}$ and have also reported deteriorating mental and physical health status related to the role as informal caregivers. ${ }^{8}$ Further, caregivers also seek healthcare to a greater extent than non-caregivers. ${ }^{8}$

Since living with HF is a stressful event for both the patient and the partner, the level of perceived control over the HF is an important coping response. Perceived control can be defined as a self-generated belief that a person has the internal resources to influence adverse events positively and bring about a desired change in his/her environment. ${ }^{9}$ High levels of perceived control are related to a better adaptation to HF, and associated with better physical health status and fewer symptoms of depression in the patients. ${ }^{10}$ Low perceived control is associated with poorer self-care activities and is independently associated with physical and 
mental health status. ${ }^{11}$ Several studies found that partners experience lower perceived control than the HF patients themselves. ${ }^{12,13}$ If a person can regain control, then they are more likely to manage self-care, which can improve both physical and mental health status. ${ }^{11}$

Perceived control is also of importance for caregivers when they support their ill family members' managing heart problems. Caregivers' perceptions of control have been related to their mental health status, where low control leads to mental distress. ${ }^{14}$ Bakas et al found that low caregiver perceived control over their family member's heart problems was reported by 42.9\% of the caregivers. ${ }^{7}$ The burden of caregiving has been found to be lower when the patient experiences better mental and physical health and when the partner experiences higher control over the heart disease. ${ }^{14}$

Depressive symptoms are common among patients with HF, the prevalence ranges from 9\% to $60 \% .{ }^{15}$ Depressive symptoms are associated with impaired health status and predict medical adherence and self-care management. ${ }^{16}$ Depressive symptoms have also been found to be associated with reduced physical activity in patients with HF because of the lack of motivation. ${ }^{16,17}$ Caregivers experience depression commonly and the levels of depressive symptoms and prevalence of depressive symptoms are very similar to those of patients with $\mathrm{HF}^{8,}, 14$

Thus, there is limited knowledge about how depressive symptoms affect the relationship between perceived control over HF and physical and mental health in both patients and partners.

Chung et $\mathrm{al}^{18}$ found that perceived social support and depressive symptoms were independent predictors of physical and mental health in patients with HF, and neither social support nor 
depressive symptoms moderated quality of life. Doering et $\mathrm{al}^{19}$ found that depressive symptoms was a mediator between perceived control and both general and cardiac specific mental and physical health and concluded that high control was associated with improved depressive symptoms in heart transplant recipients. In this study, we assumed that depressive symptoms play a role of mediation in the relationship between perceived control and health status and this phenomenon may be same for both patients and partners.

Thus, the aim of this study was to examine whether the relationship between perceived control and health status (i.e., mental and physical) was mediated by depressive symptoms in patients with HF and their partners.

\section{Methods}

\section{Design and settings}

This study is a secondary data analysis using the baseline assessment data from a randomized controlled intervention study (ClinicalTrials.gov, identifier: NCT02398799). ${ }^{20}$ Patients with HF and their partners were recruited at a university hospital and a county hospital in the southeast of Sweden between 2005 and 2008. In the present study, only patients and partners who had completed data of key variables (i.e., depressive symptoms, perceived control, and health status) in the baseline assessment were selected. The study conforms with the principles outlined in the Declaration of Helsinki and was approved by the Regional Ethical Review Board in Linköping, Sweden (No. 03-568, No.M178-04).

\section{Sample and procedures}

Eligible participants were individuals diagnosed with HF (NYHA class II-IV) according to guidelines ${ }^{1}$ with a partner cohabiting in the same household. Exclusion criteria were diagnosed dementia in one of the dyad members or other severe psychiatric illness, drug 
abuse, difficulties to understand or read the Swedish language, planned cardiac surgery or participation in other studies.

Patients and their partners were informed verbally about the study at a visit at the HF clinic or by phone. Those interested in taking part in the study were given additional written information. Both patients and partners signed informed consent and separate questionnaire packets were sent by post to the patient and partner to complete at home.

\section{Measures and data collection}

The following instruments were used; Control Attitude Scale, ${ }^{21}$ Beck Depression Inventory ${ }^{22}$ and 36- item Short-Form Health Survey. ${ }^{23}$ In addition, demographic data and health history were collected, using a structured questionnaire, to describe sample characteristics.

\section{Perceived control}

Control Attitude Scale (CAS) consists of 4 items, two of which reflect the patient's perceptions and two reflect the patient's perception about family members' perceived control and vice versa for the partners. Response statements were scored on a scale from 1 (none) to 7 (very much). The total score ranges from 4 to 28, with higher scores reflecting higher levels of perceived control. The CAS-English version has been reported as a reliable instrument as Cronbach's alpha values ranging from 0.77 to $0.89 .^{21}$ The psychometric testing for the Swedish translation has shown reliability coefficient alpha $>0.80$ for the patient version and

0.60 to 0.70 for the partner version. ${ }^{24}$ In the present study Cronbach's alpha was 0.80 for both the patient and the partner version.

\section{Depressive symptoms}


Beck Depression Inventory II (BDI-II) was used to assess depressive symptoms. ${ }^{22}$ Each answer is scored on a scale from 0 to 3, indicating feelings over the last two weeks. Higher scores indicated more severe depressive symptoms. The cut off scores recommended by the developer are: 0-13: no depression; 14-19: mild depression; 20-28: moderate depression; and 29-63: severe depression. A Swedish version of the BDI-II has been validated. ${ }^{25}$ In this study, Cronbach’s alpha was 0.92 in patients and 0.90 in the partners.

\section{Health status}

The Short-Form-36 (SF-36) was used to assess physical and mental health status. ${ }^{23}$ SF-36 consists of 36 items which measure eight health concepts: physical function, role limitation caused by physical problems, bodily pain, general health, social function, mental health, role limitation caused by emotional problems, and vitality. A standard scoring algorithm can be used to aggregate scores from the eight health components into two higher order summary scores, the physical component summary (PCS) and the mental component summary (MCS). The MCS comprise a summary of four subscales based on a wide variety of different item in SF-36 namely social function, mental health, role limitation caused by emotional problems, and vitality. The PCS compromise a summary of physical function, role limitation caused by physical problems, bodily pain, general health. The PCS and MCS have 0 as the lowest possible score, but in contrast to the eight health components, they cannot reach 100 . In the present study, PCS and MCS were used to assess physical and mental health status. The SF36 has been frequently used and has been found to have good reliability and validity. ${ }^{23}$

\section{Data analysis}

Descriptive statistics (frequency, mean, standard deviation, median, range) were used to describe demographic and clinical characteristics of participants. Associations between 
depressive symptoms, perceived control, and physical and mental health status were assessed using Pearson’s correlation.

To examine the mediator effect of depressive symptoms we used a linear regression approach guided by Baron and Kenny. ${ }^{26}$ Analyses were conducted separately for patients and partners. ${ }^{26,27}$ In the first step, the outcome variable (i.e. mental or physical health status) was regressed on the independent variable (perceived control). This indicates the total effect of the predictor on the outcome variable. In the second step, the mediator variable (depressive symptoms) was regressed on the independent variable (perceived control), and then in the third step, the outcome variable was regressed on the mediator variable. In the final step, the outcome variable (i.e. mental or physical health status) was regressed on the mediator (depression) and the independent variable (perceived control). A mediator effect is supported when the significant association between the independent variable (perceived control) and outcome variable (i.e. mental or physical health status) becomes less significant or nonsignificant when both independent variable and mediator are entered in the regression model (step four). We used the Sobel test to confirm significance of mediator effect using the web page MedGraph. ${ }^{28}$ The MedGraph also provides information for total effect of predictor on outcomes, direct (i.e., predictor) and indirect (i.e., mediator) effects on the outcomes. The level of statistical significance was set to $p<0.05$. Statistical analyses were conducted using SPSS 18 for Windows (SPSS Inc, Chicago, IL, USA).

\section{Results}

\section{Characteristics of the participants}

The final sample consisted of 132 patients and their cohabiting partners. The majority of the patients were men (75\%) while the majority of partners were women (75\%). Patients were two years older than their partners $(69.4( \pm 13.6)$ vs. $67.1( \pm 12.1)$ years. Half of the patients were classified in NYHA III (59.1\%) (Table 1). 
Insert Table 1. Clinical and demographic characteristics of the patients and the partners.

\section{Mediation effect of depressive symptoms on the relationship between perceived control and mental health status}

\section{Patients}

In a series of four linear multiple regressions, we found a significant mediator effect of depressive symptoms in the relationship between perceived control and mental health in patients (Table 2). Perceived control predicted mental health status $(\beta=.357, p=.001)$ in step one and perceived control also predicted depressive symptoms $(\beta=.336, p=.001)$ in step two. In step three, depressive symptoms predicted mental health $(\beta=-.651, p=.001)$. When we entered both perceived control and depressive symptoms in prediction of mental health status, the standardized regression coefficient for the association decreased from $\beta=.357$ to $\beta=.155$ but remained significant in step four $(p=.028)$. The Sobel test also confirmed the significant mediator effect of depressive symptoms (sobel z score $=3.67, p=.001$ ). The indirect to total effect ratio indicated that $63 \%$ of the total effect were explained by depressive symptoms (i.e. the mediator variable, Figure 1).

Insert Table 2. Mediator effect of depressive symptoms on the relationship between perceived control and mental health status in patients $(n=132)$ and

Insert Figure 1. Mediator effect of depressive symptoms on mental and physical well-being on patients and partners.

\section{Partners}

We also found a significant mediator effect of depressive symptoms in the relationship between perceived control and mental health for partners (Table 3). Partners' perceived control did not reach statistical significance in predicting mental health status $(\beta=.158, p=$ .064) in step one. Though in step two, partners perceived control predicted depressive 
symptoms ( $\beta=.196, p=.021)$, and in step three, depressive symptoms predicted mental health ( $\beta=-.548, p=.001)$. When we entered both perceived control and depressive symptoms in prediction of mental health, the standard coefficient value of perceived control was decreased $(\beta=.053, p=.072)$, while depressive symptoms remained as a strong predictor of mental health $(\beta=-.538, p=.001)$. The Sobel test indicated significant mediator effect of depressive symptoms $(p=.026)$. The indirect to total effect ratio indicated that $66 \%$ of the total effect were explained by depressive symptoms (Figure 1).

Insert Table 3. Mediator effect of depressive symptoms on the relationship between perceived control and mental health status in partners $(n=132)$.

\section{Mediation effect of depressive symptoms on the relationship between perceived control and physical health status}

\section{Patients}

In a series of four linear multiple regressions, we found a significant mediator effect of depressive symptoms in the relationship between perceived control and physical health in patients (Table 4). In step one of the mediation analysis, perceived control significantly predicted physical health status $(\beta=.187, p=.032)$ and perceived control also predicted depressive symptoms ( $\beta=-.341, p=.001)$ in step two. In step three, depressive symptoms predicted physical health $(\beta=-.335, p=.001)$. In the final step, when both perceived control and depressive symptoms were entered, only depressive symptoms remained as a significant predictor of physical health status, thus demonstrating that depressive symptoms were a mediator of the relationship between perceived control and physical health status ( $\beta=-.306$, $p=.001$ ). The Sobel test was significant (sobel z score $=2.69, p=.007$ ). The indirect to total effect ratio indicated that $56 \%$ of the total effect were explained by depressive symptoms (Figure 1). 
Insert Table 4. Mediator effect of depressive symptoms on the relationship between perceived control and physical health status in patients $(\mathrm{n}=132)$

\section{Partners}

We found no significant mediator effect of depressive symptoms in the relationship between perceived control and physical health in partners. Perceived control did not reach statistical significance in predicting physical health $(\beta=.004, p=.959)$, or depressive symptoms $(\beta=$ .033, $p=.708)$. Though, depressive symptoms predicted physical well-being ( $\beta=.178, p=$ .037). When entering both perceived control and the mediator depressive symptoms, both variables predicted physical well-being (perceived control $\beta=.041, p=.036$; depressive symptoms $\beta=.186, p=.033$ ). That indicates, depressive symptoms were not significant as a mediator but played a role as an enhancer in the relationship of perceived control with physical health status.

Insert table 5. Mediator effect of depressive symptoms on the relationship between perceived control and physical health status in partners $(n=132)$

\section{Discussion}

To the best of our knowledge, this is the first study to examine if the relationship between perceived control and health status are mediated by depressive symptoms in patients with HF and their partners. Overall, our findings showed that depressive symptoms mediated this association for both patients and partners.

We found a mediator effect of depressive symptoms in the relationship between perceived control and mental health status in both patients and partners. Psychological problems are common in patients with HF, for example one in every five HF patients experience depressive symptoms. ${ }^{15}$ Patients with higher levels of perceived control have been found to experience 
fewer symptoms of depression compared to patients who experience lower levels of perceived control. ${ }^{29}$ This result indicates that patients experiencing depressive symptoms and low control are at risk for impaired mental health status. This could also reflect on the fact that we also found that depressive symptoms were a mediator in the relationship between perceived control and physical health status for the patients. Goldstein et al. found that individuals with higher levels of depressive symptoms, more regimen complexity was associated with lower medical adherence, which affect the outcome. ${ }^{16}$

Depressive symptoms have previously been associated with poor engagement in self-care management and decreased quality of life in patients with HF. Self-care influences both medical and person-centred outcomes, such as well-being, quality of life, readmission rates and mortality. ${ }^{30}$ Effective HF self-care is important for maintaining health and to prevent patients from HF exacerbation. ${ }^{30}$ HF- specific self-care behaviors include taking prescribed medications, keeping physically active, eating healthy, avoiding excessive salt, fluid and alcohol intake, and maintaining a healthy body weight. Self-care management also includes daily monitoring and recognition of changes in signs and symptoms, knowing how and when to contact healthcare professionals and, in line with professional advice, know when to selfmanage diuretic therapy. ${ }^{1}$ Individuals with depression may have distinct problems in performing self-care due to impaired motivation. It is known that HF patients with depressive symptoms might not be optimal candidates for regular self-care interventions. ${ }^{16}$ To help patients with depressive symptoms and their partners to be able to manage the self-care the they may need diverse types of support. To improve outcomes, individualized and more targeted interventions, which address both practical and mental components, are probably needed.

Also in patients with other chronic disease affecting the heart and lungs, low levels of perceived control have been shown to negatively affect depressive symptoms and health 
status. Higher levels of perceived control are related to less depressive symptoms in patients with coronary heart disease ${ }^{29}$ and with less severe depressive symptoms in asthma patients. ${ }^{31}$ The result in the present study highlights the importance of increasing the patients and partners perceived control over their heart disease. Perceived control is a relevant target for nursing interventions since increased control may reduce complications, and has been found to be sensitive to psychosocial and educational interventions in both patients and partners. These findings also highlights the importance of including partners in the HF programs. ${ }^{9,} 31$ The level of perceived control could be easily measured by for example the CAS. ${ }^{21}$ The CAS instrument consists of four belief statements designed to measure perceptions of personal and family control (and conversely helplessness) in the context of cardiovascular disease, and could be used for both patients and partners.

Surprisingly, for partners, perceived control failed to predict their own mental health. One reason for that could be that the partners in this study scored relatively high levels of perceived control and low levels of depressive symptoms.

However, partners' perceived control predicted their depressive symptoms, meaning that partners with low control are at risk for depressive symptoms. Relatively high levels of depressive symptoms and deteriorating mental health have been identified among partners, sometimes even higher than in the HF patients. ${ }^{6}$ Depressive symptoms and partners mood states can have detrimental effect on HF patients self-care ability. ${ }^{32}$ Patients with moderate to severe HF are often reliant on their partners for assistance with self-care activities, meaning that also partners need knowledge about disease management. There is a relationship between the amount of care provision and partners health, and when the burden increases, so does the risk of illness among partners. ${ }^{7}$ This call for a family-oriented approach in which nurses also assess the way that family members are affected by the HF of the patient. Education and skills training for both patients and partners seem to be highly necessary to improve the level of 
control of the HF. Also, screening and treatment of depressive symptoms is important in improving both patients and partners mental health status and self-care among HF patients. Screening depressive symptoms for both patients and partners living with HF are still rare in clinical practice.

This study has limitations that affect generalizability. Because this study is a secondary data analysis, data was collected some years ago. However, screening for depression is still rare in clinical practise for patients and partners living with HF. Further, since this was a crosssectional study, no causal relationship could be established. Using both MCS and BDI in the same mediation analysis can be questioned. However, MCS and BDI measure different, but somewhat overlapping concepts, with the correlation 0.55 for partners and 0.66 for partners. Beck Depression Inventory is defined as a depression screening instrument with a strong correlation with the clinical assessment for depression, while the MCS comprise a summary of four subscales based on a wide variety of different item in SF-36 namely social function, mental health, role limitation caused by emotional problems, and vitality. In the study sample there was an unequal gender distribution, where the majority of the patients were male with female spouses. Therefore, we cannot exclude the possibility that our findings to some extent may reflect gender differences. In previous research there has been inconclusive findings regarding the relationship between gender, perceived control and depressive symptoms. Chung et $\mathrm{al}^{33}$ found that caregivers' perceived control predicted their depressive symptoms and this was not related to gender. While Rohrbaugh et al ${ }^{12}$ found that both female patients and partners experienced more distress and depressive symptoms than their male counterparts. Further studies using longitudinal study designs are needed to determine whether there is a gender difference rather than a patient/partner difference regarding perceived control and depressive symptoms. 
The data were collected in one academic hospital and one county hospital in Sweden so that it is limited to generalize in patients with HF in another context. Further, the current study only included spouses and no other family members. More research is needed including other informal caregivers, for example children or other persons supporting patients with HF. 


\section{References}

1. Ponikowski P, Voors AA, Anker SD, et al. 2016 ESC Guidelines for the diagnosis and treatment of acute and chronic heart failure: The Task Force for the diagnosis and treatment of acute and chronic heart failure of the European Society of Cardiology (ESC). Developed with the special contribution of the Heart Failure Association (HFA) of the ESC. Eur J Heart Fail 2016. 2. Lamura G, Mnich E, Nolan M, et al. Family carers' experiences using support services in Europe: empirical evidence from the EUROFAMCARE study. The Gerontologist 2008; 48: 752771.

3. Buck HG, Kitko L and Hupcey JE. Dyadic heart failure care types: qualitative evidence for a novel typology. J Cardiovasc Nurs 2013; 28: E37-46.

4. Buck HG, Harkness K, Wion R, et al. Caregivers' contributions to heart failure self-care: a systematic review. European journal of cardiovascular nursing : journal of the Working Group on Cardiovascular Nursing of the European Society of Cardiology 2015; 14: 79-89.

5. Hogstel M, Curry L and Walker C. Caring for older adults, the benefits of informal family caregiving. J Theory Construct Test 2005; 9: 55-60.

6. Stromberg A and Luttik ML. Burden of caring: risks and consequences imposed on caregivers of those living and dying with advanced heart failure. Curr Opin Support Palliat Care 2015; 9: 26-30.

7. Bakas T, Pressler SJ, Johnson EA, et al. Family caregiving in heart failure. Nurs Res 2006; 55: 180-188.

8. Ho SC, Chan A, Woo J, et al. Impact of caregiving on health and quality of life: a comparative population-based study of caregivers for elderly persons and noncaregivers. $J$ Gerontol A Biol Sci Med Sci 2009; 64: 873-879.

9. Moser DK and Dracup K. Impact of cardiopulmonary resuscitation training on perceived control in spouses of recovering cardiac patients. Res Nurs Health 2000; 23: 270-278.

10. Arestedt K, Agren S, Flemme I, et al. A psychometric evaluation of the four-item version of the Control Attitudes Scale for patients with cardiac disease and their partners. European journal of cardiovascular nursing : journal of the Working Group on Cardiovascular Nursing of the European Society of Cardiology 2015; 14: 317-325.

11. Heo S, Lennie TA, Pressler SJ, et al. Factors associated with perceived control and the relationship to quality of life in patients with heart failure. European journal of cardiovascular nursing : journal of the Working Group on Cardiovascular Nursing of the European Society of Cardiology 2015; 14: 137-144.

12. Rohrbaugh MJ, Cranford JA, Shoham V, et al. Couples coping with congestive heart failure: role and gender differences in psychological distress. J Fam Psychol 2002; 16: 3-13.

13. Moser DK and Dracup K. Role of spousal anxiety and depression in patients' psychosocial recovery after a cardiac event. Psychosom Med 2004; 66: 527-532.

14. Ågren S, Evangelista L and Stromberg A. Do partners of patients with chronic heart failure experience caregiver burden? European journal of cardiovascular nursing : journal of the Working Group on Cardiovascular Nursing of the European Society of Cardiology 2010; 9: 254262.

15. Rutledge T, Reis VA, Linke SE, et al. Depression in heart failure a meta-analytic review of prevalence, intervention effects, and associations with clinical outcomes. J Am Coll Cardiol 2006; 48: 1527-1537.

16. Goldstein CM, Gathright EC, Gunstad J, et al. Depressive symptoms moderate the relationship between medication regimen complexity and objectively measured medication adherence in adults with heart failure. J Behav Med 2017; 40: 602-611.

17. Alosco ML, Spitznagel MB, Miller L, et al. Depression is associated with reduced physical activity in persons with heart failure. Health Psychol 2012; 31: 754-762. 
18. Chung ML, Moser DK, Lennie TA, et al. Perceived social support predicted quality of life in patients with heart failure, but the effect is mediated by depressive symptoms. Qual Life Res 2013; 22: 1555-1563.

19. Doering LV, Chen B, Deng M, et al. Perceived control and health-related quality of life in heart transplant recipients. European journal of cardiovascular nursing : journal of the Working Group on Cardiovascular Nursing of the European Society of Cardiology 2017:

1474515117749225.

20. Liljeroos M, Agren S, Jaarsma T, et al. Long Term Follow-Up after a Randomized Integrated Educational and Psychosocial Intervention in Patient-Partner Dyads Affected by Heart Failure. PloS one 2015; 10: e0138058.

21. Moser DK and Dracup K. Psychosocial recovery from a cardiac event: the influence of perceived control. Heart Lung 1995; 24: 273-280.

22. Beck AT, Ward CH, Mendelson M, et al. An inventory for measuring depression. Arch Gen Psychiatry 1961; 4: 561-571.

23. Ware JE, Snow KK, Kosinski M, et al. SF-36® Health Survey Manual and Interpretation Guide. The Health Institute, Boston: New England Medical Center, 1993. .

24. Årestedt K, Ågren S, Flemme I, et al. Oral Psychometric properties of the Swedish version of the Control Attitudes Scale for patients with cardiac disease and their family members.

European journal of cardiovascular nursing : journal of the Working Group on Cardiovascular Nursing of the European Society of Cardiology 2010; 9: S26-S27.

25. Beck AT SR BG. Manual for the Beck depression Inventory-II (svensk version). Sandviken: Psykologiförlaget, 2005.

26. Baron RM and Kenny DA. The moderator-mediator variable distinction in social psychological research: conceptual, strategic, and statistical considerations.J Pers Soc Psychol 1986; 51: 1173-1182.

27. PE. J. Doing Statistical Mediation \& Moderation. New York, NY: The Guilford Press, 2013.

28. Jose PE. MedGraph-I: A programme to graphically depict mediation among three variables: The internet

version, version 3.0., (2013).

29. Moser DK, Riegel B, McKinley S, et al. The Control Attitudes Scale-Revised: psychometric evaluation in three groups of patients with cardiac illness. Nurs Res 2009; 58: 42-51.

30. Jonkman NH, Westland H, Groenwold RH, et al. Do Self-Management Interventions Work in Patients With Heart Failure? An Individual Patient Data Meta-Analysis. Circulation 2016; 133: 1189-1198.

31. Olajos-Clow J, Costello E and Lougheed MD. Perceived control and quality of life in asthma: impact of asthma education. J Asthma 2005; 42: 751-756.

32. Buck HG, Mogle J, Riegel B, et al. Exploring the Relationship of Patient and Informal Caregiver Characteristics with Heart Failure Self-Care Using the Actor-Partner Interdependence Model: Implications for Outpatient Palliative Care. J Palliat Med 2015; 18: 1026-1032.

33. Chung ML, Pressler SJ, Dunbar SB, et al. Predictors of depressive symptoms in caregivers of patients with heart failure. J Cardiovasc Nurs 2010; 25: 411-419. 
Table 1. Clinical and demographic characteristics of the dyads.

\begin{tabular}{|c|c|c|}
\hline Characteristics & Patient $(n=132)$ & Partner $(n=132)$ \\
\hline Female, n (\%) & $31(23.5)$ & $101(76.5)$ \\
\hline Age, mean (SD) & $71.3(11.5)$ & $68.8(12.5)$ \\
\hline \multicolumn{3}{|l|}{ Medical history n (\%) } \\
\hline Myocardial infarction & $57(43.2)$ & $13(9.8)$ \\
\hline Hypertension & $61(46.2)$ & $54(40.9)$ \\
\hline Diabetes & $37(28.0)$ & 17 (12.9) \\
\hline Stroke & $19(14.4)$ & $9(6.8)$ \\
\hline Lung disease & $10(7.6)$ & $10(7.6)$ \\
\hline Pacemaker & $20(15.2)$ & $2(1.5)$ \\
\hline Cardiac resynchronization therapy & $23(17.4)$ & $1(0.8)$ \\
\hline Implantable cardioverter & $5(3.8)$ & $7(5.3)$ \\
\hline \multicolumn{3}{|l|}{ defibrillator } \\
\hline Percutaneous coronary intervention & 25 (18.9) & $7(5.3)$ \\
\hline Coronary artery bypass surgery & $29(21.0)$ & $5(3.8)$ \\
\hline \multicolumn{3}{|l|}{ NYHA class. n (\%) } \\
\hline II & $37(28.1)$ & \\
\hline III & $77(58.3)$ & \\
\hline IV & $18(13.6)$ & \\
\hline \multicolumn{3}{|l|}{ Medication. n (\%) } \\
\hline ACEI/ARB & $130(98.5)$ & \\
\hline Beta-blockers & 125 (94.7) & \\
\hline Diuretics & $122(92.4)$ & \\
\hline
\end{tabular}


Full time

Disability pension/sick leave

Homemaker

Pension

Lifestyle. n (\%)

Smoking

Alcohol Never drink alcohol

$\leq 7$ glass/week

$>7$ glass/week

Exercise $<30 \mathrm{~min} /$ week

30 min-3 hours/week

$>3$ hours/week
$13(9.8)$

$13(9.8)$

$5(3.7)$

$3(2.2)$

$103(78.2)$

$2(1.6)$

$94(71.2)$

$6(4.5)$

$15(11.3)$

$32(24.2)$

$29(22.0)$

$93(70.5)$

97 (73.5)

7 (5.3)

$6(4.5)$

36 (27.3)

$7(5.3)$

57 (43.2)

51 (38.6)

39 (29.5)

74 (56.1)

\section{Instruments}

PCS, mean (SD)

32.7 (9.4)

46.4 (11.3)

MCS, mean (SD)

$41.1(12.7)$

46.2 (11.5)

BDI, mean (SD)

$11.5(8.8)$

$7.44(6.7)$

CAS, mean (SD)

$16.1(5.2)$ 
Table 2. Mediator effect of depressive symptoms on the relationship between perceived control and mental health status in patients $(n=132)$

\begin{tabular}{|c|c|c|c|c|c|c|c|}
\hline & Predictor & Outcome & $\begin{array}{l}\text { Standardized } \\
\beta\end{array}$ & $\begin{array}{l}\text { Unstandardized } \\
\beta\end{array}$ & $\begin{array}{l}\text { Std. } \\
\text { error }\end{array}$ & $\begin{array}{l}p- \\
\text { value }\end{array}$ & R2 \\
\hline $\begin{array}{l}\text { Step } \\
1\end{array}$ & $\begin{array}{l}\text { Perceived } \\
\text { control }\end{array}$ & $\begin{array}{l}\text { Mental } \\
\text { health }\end{array}$ & .357 & .953 & .219 & .001 & .127 \\
\hline $\begin{array}{l}\text { Step } \\
2\end{array}$ & $\begin{array}{l}\text { Perceived } \\
\text { control }\end{array}$ & $\begin{array}{l}\text { Depressive } \\
\text { Symptoms }\end{array}$ & .336 & -.615 & .151 & .001 & .113 \\
\hline $\begin{array}{l}\text { Step } \\
3\end{array}$ & $\begin{array}{l}\text { Depressive } \\
\text { Symptoms }\end{array}$ & $\begin{array}{l}\text { Mental } \\
\text { health }\end{array}$ & -.651 & -.952 & .097 & .001 & .424 \\
\hline $\begin{array}{l}\text { Step } \\
4\end{array}$ & $\begin{array}{l}\begin{array}{l}\text { Perceived } \\
\text { control }\end{array} \\
\text { Depressive } \\
\text { Symptoms }\end{array}$ & $\begin{array}{l}\text { Mental } \\
\text { health }\end{array}$ & -.599 & -.875 & .186 & .028 & .445 \\
\hline
\end{tabular}


Table 3. Mediator effect of depressive symptoms on the relationship between perceived control and mental health status in partners $(n=132)$.

\begin{tabular}{|c|c|c|c|c|c|c|c|}
\hline & Predictor & Outcome & $\begin{array}{l}\text { Standardized } \\
\beta\end{array}$ & $\begin{array}{l}\text { Unstandardized } \\
\beta\end{array}$ & $\begin{array}{l}\text { Std. } \\
\text { error }\end{array}$ & $\begin{array}{l}p- \\
\text { value }\end{array}$ & $\mathrm{R} 2$ \\
\hline $\begin{array}{l}\text { Step } \\
1\end{array}$ & $\begin{array}{l}\text { Perceived } \\
\text { control }\end{array}$ & $\begin{array}{l}\text { Mental } \\
\text { health }\end{array}$ & .158 & .333 & .178 & .064 & .025 \\
\hline $\begin{array}{l}\text { Step } \\
2\end{array}$ & $\begin{array}{l}\text { Perceived } \\
\text { control }\end{array}$ & $\begin{array}{l}\text { Depressive } \\
\text { Symptoms }\end{array}$ & .196 & -.252 & .108 & .021 & .038 \\
\hline $\begin{array}{l}\text { Step } \\
3\end{array}$ & $\begin{array}{l}\text { Depressive } \\
\text { Symptoms }\end{array}$ & $\begin{array}{l}\text { Mental } \\
\text { health }\end{array}$ & -.548 & -.898 & .117 & .001 & .301 \\
\hline $\begin{array}{l}\text { Step } \\
4\end{array}$ & $\begin{array}{l}\text { Perceived } \\
\text { control } \\
\text { Depressive } \\
\text { Symptoms }\end{array}$ & $\begin{array}{l}\text { Mental } \\
\text { health }\end{array}$ & -.538 & -.881 & .154 & .072 & .303 \\
\hline
\end{tabular}


Table 4. Mediator effect of depressive symptoms on the relationship between perceived control and physical health status in patients $(n=132)$

\begin{tabular}{|c|c|c|c|c|c|c|c|}
\hline & Predictor & Outcome & $\begin{array}{l}\text { Standardized } \\
\beta\end{array}$ & $\begin{array}{l}\text { Unstandardized } \\
\beta\end{array}$ & $\begin{array}{l}\text { Std. } \\
\text { error }\end{array}$ & $\begin{array}{l}\underline{p-} \\
\text { value }\end{array}$ & R2 \\
\hline $\begin{array}{l}\text { Step } \\
1\end{array}$ & $\begin{array}{l}\text { Perceived } \\
\text { control }\end{array}$ & $\begin{array}{l}\text { Physical } \\
\text { health }\end{array}$ & .187 & .363 & .167 & .032 & .035 \\
\hline $\begin{array}{l}\text { Step } \\
2\end{array}$ & $\begin{array}{l}\text { Perceived } \\
\text { control }\end{array}$ & $\begin{array}{l}\text { Depressive } \\
\text { Symptoms }\end{array}$ & -.341 & -.625 & .149 & .001 & .116 \\
\hline $\begin{array}{l}\text { Step } \\
3\end{array}$ & $\begin{array}{l}\text { Depressive } \\
\text { Symptoms }\end{array}$ & $\begin{array}{l}\text { Physical } \\
\text { health }\end{array}$ & -.335 & -.356 & .088 & .001 & .112 \\
\hline $\begin{array}{l}\text { Step } \\
4\end{array}$ & $\begin{array}{l}\text { Perceived } \\
\text { control } \\
\text { Depressive } \\
\text { Symptoms }\end{array}$ & $\begin{array}{l}\text { Physical } \\
\text { health }\end{array}$ & -.306 & -.326 & .171 & .340 & .118 \\
\hline
\end{tabular}


Table 5. Mediator effect of depressive symptoms on the relationship between perceived control and physical health status in partners $(n=132)$

\begin{tabular}{|c|c|c|c|c|c|c|c|}
\hline & Predictor & Outcome & $\begin{array}{l}\text { Standardized } \\
\beta\end{array}$ & $\begin{array}{l}\text { Unstandardized } \\
\beta\end{array}$ & $\begin{array}{l}\text { Std. } \\
\text { error }\end{array}$ & $\begin{array}{l}p- \\
\text { value }\end{array}$ & R2 \\
\hline $\begin{array}{l}\text { Step } \\
1\end{array}$ & $\begin{array}{l}\text { Perceived } \\
\text { control }\end{array}$ & $\begin{array}{l}\text { Physical } \\
\text { health }\end{array}$ & .004 & .009 & .171 & .959 & .007 \\
\hline $\begin{array}{l}\text { Step } \\
2\end{array}$ & $\begin{array}{l}\text { Perceived } \\
\text { control }\end{array}$ & $\begin{array}{l}\text { Depressive } \\
\text { Symptoms }\end{array}$ & .033 & .039 & .105 & .708 & .113 \\
\hline $\begin{array}{l}\text { Step } \\
3\end{array}$ & $\begin{array}{l}\text { Depressive } \\
\text { Symptoms }\end{array}$ & $\begin{array}{l}\text { Physical } \\
\text { health }\end{array}$ & .178 & .276 & .131 & .037 & .112 \\
\hline $\begin{array}{l}\text { Step } \\
4\end{array}$ & $\begin{array}{l}\text { Perceived } \\
\text { control } \\
\text { Depressive } \\
\text { Symptoms }\end{array}$ & $\begin{array}{l}\text { Physical } \\
\text { health }\end{array}$ & .041 & .081 & .172 & .036 & .182 \\
\hline
\end{tabular}


Mediator effect of putients sdepressive symptoms en meatal well being

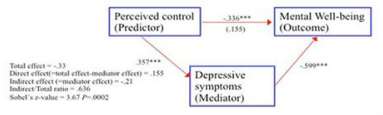

Mediafor effect of spouses depressive nympicms en mental well being

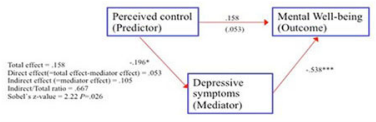

Modiater efloct of patienti depeesesve sympeons as physieat uell-beine.

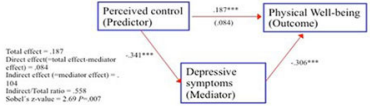

